\title{
THE SPECIFIC OF MODERN ARTISTRY PARADIGM
}

\author{
Elena Rubtsova \\ Prof. PhD., Ural Federal University, Ekaterinburg, Russia, rbtsvelena@rambler.ru
}

\begin{abstract}
Art as a human activity has always been part of human activity. It has developed together with humanity and its interest in expressing spiritual needs in multitudes of forms. From a historical point of view, these spiritually originated objects largely pleased the senses and evoked different responses in the consumer. They are, to a large extent, a reflection of development and ideas of beauty as well as human emotions. However, quite likely as a response to the devastation of two world wars that caused enormous suffering and destruction as well as the rise of entirely opposite social systems separated by ideologies, the second half of the XX century witnessed the birth of a new art-making concept. Avant-garde, as it was called, gave and is still giving a signal for a counter-run defying well-established theory and practice. For instance, Dadaism with the variety and ambiguity observed in the different procedural means to achieve artwork, as well as the directions they signal, pose quite a difficult problem for their inclusion within a specific art paradigm if philosophers constraint their ideas to what is conceived as art as a historical category. Much the same could be said about the conceptual framework advanced by J. Cage, M. Kagel, and K. Stockhausen, just three of the many representatives of the movement, that see art far from what was widely accepted as such. Many, from the consumers' point of view, as well as not few in the art world, do not seem to understand this new paradigm, its ideas, theory, and practice. The present paper systematizes some of the main manifestations, characteristics as well as the essence of the avant-garde as a well-established movement and advocates for its recognition as different from mainstream art concepts.
\end{abstract}

Keywords: art, art paradigm, work of art, artistry, aesthetics.

\section{MAIN TEXT}

Art manifestations date back to the first-day man started to live in communities. All accounted human social formations have expressed the real and spiritual needs, or both, in the forms of pictures, music, or simple objects such as weapons or clothes that satisfy different criteria and allow for their classification as art belonging to a given period of human development. That is, art was identified in the object and responses it provoked. However, this art-equals-object paradigm has, for more than seven decades, been contested by new manifestations in art practice that demand consideration in the light of the misunderstandings engendered by the concepts it proclaims to embrace.

Since the second half of the $X X$ century, real art practice acts as the certificate of essentially new situations in art life that indicate the need of theoretical reconsideration of an artistry problem. This turn in artistic vision is quite likely the result of the existing social condition after two world wars that brought with them suffering, destruction, and death as well as the rise of a bipolar world based on ideological contraries. From that moment on, artists have accompanied their creations with theoretical research while trying to clarify the 
possibility of new artistic visions; in other words, the concept of art, in much of its realization, changed, and as a result, that of artwork has become problematic nowadays.

However, unlike authors, critics, or other agents in the art world such as recipients do not always appreciate such creations as artwork in modern culture. Beliefs and conceptions of what artwork is have not changed despite the more than one hundred years of Avant-Garde. D. Marzona (2005: 6) assertion that the artistic heterogeneous approaches involved in Conceptual Art have proved to be so multifaceted that it would be impossible to talk of a unitary style or even an artistic movement. In the author's opinion, this seems to be the main theoretical issue on today's art practices acceptance in general.

These practices have led to the appearance of artwork that is expressed in ways never thought before, in ways that go against established beliefs and conceptions. Much artwork today is preceded by continuous action research, and the result expresses its dynamics a symbiotic relationship between the artist and the environment (Harrison \& Worden, 2004). Yet, this type of new creations is not perceived as Artwork in its own right. Long away is the moment when they will be found in museums, galleries, or the usual places where the public expects and goes to nurture the soul. On this issue, Quaranta (2013) asserts, "... the most important thing is that most of the artistic production that takes place in the 'new media art world' [as well as performances and installations], has as yet little or no visibility in the contemporary art world (p. 7; My additions)".

In today's Aesthetics, more and more attention is given to that type of art as real practice and as new experiences. Nevertheless, the variety and ambiguity of such processes as observed in different types of artwork, as well as their directions, pose a problem for their inclusion within a specific paradigm.

In this case, the concept of art paradigm helps to reconsider the historical development of creation as a continuous change of paradigms; consequently, no need for a single uniformed theory of arises. In other words, artwork outside the scope of what is considered art at a given moment is admitted as such by updating or creating a new paradigm that assumes a new quality of artistry. Therefore, paradigm, as a category in philosophical terms, constitutes a special vision of art including both the act of creativity and assessment of its results. Consequently, the adoption of such point of view allows artistry to become a historical category.

The main issue is that in the relationship theory-practice, avant-gardists see art making from a different perspective, apply different concepts and as such art making becomes an activity entailing all the process from its conception all along the road of art production to the final result. Everything within it is art. Cage illustrates part of the concept when, in The Future of Music, he explains his decision to fight for the full rights of noise after all purely musical questions stopped being serious questions, because the audience today is already adjusted to new perceptions of loudness, speed, sound, and pause. Pause, for instance, is thought of as new musical material because actually, the pause is not as empty as it is usually considered. Placing himself far from the orchestra and opera lovers, N. Frye (1990) believes, "A musical discord is not an unpleasant sound; it is a sound which throws the ear forward to the next beat: it is a sign of musical energy... (Cited by Small, p. 75)".

As a result, many avant-garde composers today no longer make musical structures. Instead, they set processes going. Theoretically, this obeys to Cage's vision of the difference between structures and processes that for him are the same as the difference between a table and the weather: "In the case of a table," he states, "the beginning and end of the whole and each of its parts is known. In the case of weather, though we notice changes in it, we have no clear knowledge of its beginning or ending (Cited by Perloff and Junkerman, 1994, p. 44)." That is, artwork is understood not as an object at the beginning, but as an infinite self-sufficient series of actions that can include the object. Therefore, the procedure, a concept attributed to music as temporary art, now extends to other art forms.

In addition, while explaining his preference for processes rather than objects, Cage states that when recognizing objects, we often do not see the processes because we see the object isolated, and we lose the feeling of life. This explains why, many nowadays composers use an uncertainty element that gives performers the chance to play it independently from the work; that is, as they wish or deem appropriate. For Cage, the piece of music becomes a musical enterprise.

Perhaps, the above and the following are the most mysterious categories of the Modern Philosophy of Art because the paradoxicality of this new type of artistry manifests itself in opposite categories such as emptiness surrounding a space filled with colour, silence surrounded with sounding, or painting representing nothing but the empty canvases as in J. Jones's and R. Rauschenberg's artwork. Their explanation comes from Cage (1973) who claims, 'Ideas are not necessary. It is more useful to avoid having one, certainly avoid having several (leads to inactivity) (p. 99)." On the other, they may have their origin in, "Having made the 
empty canvases (A canvas is never empty), Rauschenberg became the giver of gifts (Ibid, p. 103)."

Another example illustrating these paradoxes is Cage's best-known composition 4'33, where the equivalence of sound and silence is demonstrated in his Indeterminacy, a musical piece considered a theoretical manifesto and the action of silence. This work represents the stated verbal text in the form of a graphic score, each of which has thirty musical fragments that should not sound more than one minute. The texts, which are settled down in 'minutes', appear as a parable on a subject about the lack of difference between silence and sound, noise and music, freedom and the lack of it.

Unarguably, a work of art may represent an imitation of life, but not life itself; however, the borders between art and life are not constant. A. Kaprow, the developer of the Theory of Happenings, emphasizes, however, that the main objective of a Happening consists in keeping mobile while trying to distinguish the line separating art from reality as less as possible. However, the line separating art from reality and artistry from the ordinary, nevertheless, exists. In spite of that, Kaprow (1966) claims, "The fine arts traditionally demand their appreciation [by] physically passive observers, working with their minds to get at what their senses register. But the Happenings are an active art, requiring that creation and realization, artwork and appreciator, artwork and life be inseparable." In other words, the borders in each new paradigm are marked again, but they have no accurate outlines.

Expanding his ideas in a manifesto, Kaprow proclaims that the creation of a work of art should not become the purpose of the artist (Ibid). Owing to his revision of the concept, a work of art ceased to be perceived in its autonomous essence and started to be considered as the result of the communicative act involving not only the object and process but also its producer (the artist) and the consumer (the percipient). In other words, according to avant-gardists, the work of art rejects its singularity in favor of its plurality.

Conceptually, the plurality in modern art appears as an open way of action. For instance, defining the new concept of modern music, one of founders and theorists of electronic music, K. Stockhausen (1990) says that "The set of processes in a uniform work of art is a new concept [comparable only] if at the same time you observe different living beings (p. 62)." Artists create unfinished works, provoke the audience's activity, and invite them to co-author. In this sense, for example, collages do not apply for the role of the finished works when they consolidate the contents to process the establishment of diverse connections between objects, their perception, and multiple-valued sense.

Thus, today this new modern art paradigm recognizes plurality and artistry variability. It can be said this paradigm is universal and an alternative dominating the judgment of modern art phenomena. Universality assumes the existence within this latest paradigm of various, but equivalent approaches to art alongside a more widely accepted viewpoint to creativity in general. Alternativeness, on the other hand, means the possibility of this form of art to oppose the previous paradigm(s). The alternative nature of modern art strategy is demonstrated by its aspiration to contradict many traditional ideas of creativity, professionalism, skills, identity, and spirituality and, in general, all estimated values and functions of fine art. In other words, this new form acts as a mediator by choosing an intermediary role between the internal and the external, the heterogeneous and the homogeneous, the deep and the superficial. The new forms, that is to say, art as an event or art as a gesture, for instance, naturally compel to reconsider the settled ideas of artistry and their basis.

Hitherto, two directions in the realization of the transition to a universal and alternative art paradigm have been outlined. On the one hand, art is trying to come back to that universal ontological level where we are united not by culture, but with nature as Action Art tries to evoke; on the other, corporality and naturalness have become artistry signs. The Russian art researcher, V. Savchuk (2001), directly correlates modern and archaic art paradigms by claiming, "Just as works of art were released from ritual and magic practice, in Action Art, the lost ritual and magic elements come back, saving space with extra art purposes (pp. 78-79)." In this way, the symbiosis artist percipient become a reality as illustrated by Reich (1968), "While performing and listening to gradual musical processes one can participate in a particular liberating and impersonal kind of ritual. Focusing in on the musical process makes possible that shift of attention away from he and she and you and me outwards towards it."

On the other hand, while recognizing the immutable determinism of the modern world and the cultural objects that make up its reality, art is trying to overcome this reality by coming within the scope of hyperreality, where virtual artifacts act as special illusory quasi-sensual realities. For example, in the virtual art, the form changes and loses the classical definiteness through morphing as a way of transforming one object into another in a gradual continuous deformation. By becoming fluid because of the smooth transformations, the unstructured form personifies the removal of the opposition beauty-ugliness. Such transformers testify the anti-hierarchical uncertainty of virtual aesthetic objects. Non-formalization of a virtual artifact reveals, at the 
same time, essential transformations of aesthetic perception. In the centre of attention of artists and theorists, there is a perception, but not that of an artifact; there is that of a process, but not that of its result.

The universal character of the modern art paradigm as shown in the neutralization of any opposition such as progress/regress and evolution/involution leads to consider art as space where all directions are essentially equivalent; space, within which the creative subject can move freely without any restrictions. On this chessboard, all courses are mutually reciprocal. This tendency, in fact, reveals the symptoms of a generalized condition in artistry at the turn of XX and XXI centuries.

Summing up, the features characterizing avant-garde, as a modern art paradigm, are the artist's interests in the processes of art making seen as a provocation from the paradoxes it evokes. All practice within this movement demonstrates this in one way or another. On the other hand, its essence lies in its universal character and alternativeness that point to a crucial issue in today's Philosophy of Art: the lack of a single uniformed universal artistic theory.

\section{REFERENCE LIST}

Cage, J. (1973). On Robert Raucshenberg, Artist, and His Work. In Cage John. Silence. Wesleyan University Press.

Harrison D. and Worden, S. (2004). Digital Arts On (the) Line. In Digital Art History. A Subject in Transition/ Computers and the History of art, yearbook 2004, Volume 1.

Huelsenbeck, R. (1918). Dada Manifesto. http://germanhistorydocs.ghidc.org/docpage.cfm?docpage id $=4989$

Kaprow, A. (1966, 1993). The Happenings Are Dead: Long Live the Happenings! (1966). In Allan Kaprow. Essays on the Blurring of Art and Life. Berkeley, CA: University of California Press, 1993, pp. 59-65. http://www.belgiumishappening.net/home/publications/1966-0000 kaprow happeningsaredead

Marzona, D. (2006). Conceptual Art. TASCHEN GmbH.

Perloff, M., and Junkerman, Ch. (1994). John Cage. Composed in America. The University of Chicago Press. Quaranta, D. (2013). Beyond New Media Art. LINK Editions, Brescia.

Reich, S. (1968). Music as a Gradual Process. http://www.bussigel.com/systemsforplay/wpcontent/uploads/2014/02/Reich Gradual-Process.pdf

Savchuk, V.V. (2001). Konversiya iskusstva. Sankt-Peterburg : Izdatelstvo «Petropolis». 288 P.

Small, J.J. (1990). Positive as Sound: Emily Dickinson's Rhyme. University of Georgia Press. 261 P.

Stockhausen, K. (1990). Dyshat vozduhom inyh planet. Sovetskaya musica. № 10. 